\title{
Derris (Lonchocarpus) urucu (Leguminosae) Extract Modifies the Peritrophic Matrix Structure of Aedes aegypti (Diptera:Culicidae)
}

\author{
Desiely Silva Gusmão, Valéria Páscoa, Leda Mathias", Ivo José Curcino Vieira*, \\ Raimundo Braz-Filho*, Francisco José Alves Lemos $/^{+}$
}

\author{
Laboratório de Biotecnologia, Centro de Biociências e Biotecnologia *Laboratório de Química, Setor de Produtos Naturais, \\ Centro de Ciência e Tecnologia, Universidade Estadual do Norte Fluminense, Av. Alberto Lamego 2000, 28015-620 \\ Campos dos Goytacazes, RJ, Brasil
}

\begin{abstract}
Aqueous suspension of ethanol extracts of Derris (Lonchocarpus) urucu (Leguminosae), collected in the state of Amazonas, Brazil, were tested for larvicidal activity against the mosquito Aedes aegypti (Diptera:Culicidae). The aim of this study was to observe the alterations of peritrophic matrix in Ae. aegypti larvae treated with an aqueous suspension of D. urucu extract. Different concentrations of D. urucu root extract were tested against fourth instar larvae. One hundred percent mortality was observed at $150 \mu \mathrm{g} / \mathrm{ml}\left(\mathrm{LC}_{50} 17.6 \mu \mathrm{g} / \mathrm{ml}\right) 24 \mathrm{~h}$ following treatment. In response to D. urucu feeding, larvae excreted a large amount of amorphous feces, while control larvae did not produce feces during the assay period. Ultrastructural studies showed that larvae fed with $150 \mu \mathrm{g} / \mathrm{ml}$ of $\mathrm{D}$. urucu extract for $4 \mathrm{~h}$ have an imperfect peritrophic matrix and extensive damage of the midgut epithelium. Data indicate a protective role for the peritrophic matrix. The structural modification of the peritrophic matrix is intrinsically associated with larval mortality.
\end{abstract}

Key words: peritrophic matrix - larvicide - Aedes aegypti - Derris urucu - plant extract - insecticide

Despite significant advances in the techniques used for its control during recent decades, the mosquito continues to pose serious public health problems. Mosquitoes are the principal vector of a variety of serious diseases, including malaria, yellow fever, dengue, and encephalitis. Alone, malaria is estimated to kill between 1.5 and 2.7 million people every year (Beier 1998).

Insecticides have been used for vector control, mainly organic compounds in origin such as organochlorides, organophosphates, carbamates and pyrethroids. This method of control has proved to be ineffective and undesirable because of development of insect resistance and environmental pollution due to continued accumulation of the slowly degradable toxic compounds (Palchick 1996).

Co-evolution has equipped plants with a plethora of chemical defenses against insect predators. Aware of this effect, mankind has used plants or plant extracts to control insects since ancient times. Plant derived products have received increased attention from scientists and more than 2,000 plant species are already known to have insecticidal properties (Balandrin 1985, Sukamar et al. 1991).

Roots of certain tropical plants Leguminosae, especially species of Derris, have been used as insecticides. The biological activity of these roots has been attributed to a modified isoflavonoid known as rotenone (Davidson 1930). Rotenone is considered highly toxic to fish and

Financial support by CNPq, Capes, Fenorte and UNDP/World Bank/WHO Special Programme for Research and Training in Tropical Diseases.

${ }^{+}$Corresponding author. Fax: +55-24-2726.3861

E-mail: franze@uenf.br

Received 21 August 2001

Accepted 5 November 2001 many insects (Greenhalgh 1986). Other important constituents of Derris root (deguelin and tephrosin) have been shown to be toxic to insects, however they are less active than rotenone (Davidson 1930). This natural pesticide is a respiratory inhibitor acting between NAD+ and Co-enzyme Q interfering in energy production (Greenhalgh 1986, Beattie et al. 1994). A secondary detrimental effect, the induction of cell death by rotenone, has been attributed to a very advanced stage of poisoning (Lindahl \& Öberg 1961).

The peritrophic matrix (PM) is an acellular sheet that involves the food separating it from the midgut epithelium (Richards \& Richards 1977, Peters 1992, Terra 1996). There are two fundamental types of PM defined by their site of synthesis. Type I PM is produced from the midgut epithelium, often in response to feeding, while type II PM is typically constitutively synthesized by a small group of highly specialized cells in an organ called the cardia, located in the anterior midgut region. Both types of PM are composed of proteins, proteoglycans and chitin, which together form the robust structure as well as the protective and semi-permeable functions of the matrix. The PM is present in most insects at least at some stage in their lifecycle. It has important roles in facilitating the digestive process in the gut, protecting insects from invasion by viruses, bacteria, protozoa and helminthes, and protecting midgut cells from abrasive food particles (Shahabuddin et al. 1996, Tellam 1996, Lehane 1997, Terra 2001). A novel role for the PM is suggested. It may provides protection to Leishmania parasite from the action of the host digestive enzymes (Pimenta et al. 1997). It also protects the insects, at least partially, against chemical attack by potentially toxic agents with much smaller molecular dimensions (Peters 1992, Regev et al. 1996, Lehane 1997, Barbehenn \& Martin 1997). Thus, the permeability of the PM is not a matter of simple ultrafiltration related to 
pore size (Derksen \& Granados 1988). The ingested toxic chemicals may cross passively or disrupt of the PM structure, which negatively affects the insect.

The current study is part of a broader study undertaken to screen plant extracts in order to isolate new secondary metabolites for larvicidal activity. Here, we investigate by light and electron microscopy the morphology and ultrastruscture modifications of the peritrophic matrix in D. urucu-treated Aedes aegypti larvae.

\section{MATERIALS AND METHODS}

Plant collection - D. urucu was collected in the state of Amazon, Brazil.

Mosquitoes - Ae. aegypti was originally obtained from Dr Ricardo L de Oliveira, from a colony established at the Fundação Oswaldo Cruz, Rio de Janeiro, Brazil. The adults were reared in a room maintained at $27^{\circ} \mathrm{C}$ in humidified cages and provided with $10 \%$ sucrose. Larvae were reared on a ground commercial mouse food. Early fourth instar larvae were used in the experiments. The larvae were anesthetized by placing them in Petri dishes on crushed ice. Dissections were carried out in cold phosphate-buffered saline (PBS).

Extracts preparation - The roots of the plants were dried at room temperature, ground in a knife mill or in a homogenizer and extracted for $24 \mathrm{~h}$ with methanol at room temperature. The solvent was removed by rotatory evaporation at a temperature below $45^{\circ} \mathrm{C}$. The resulting crude extracts were transferred to an open vial and the residual solvent removed for at least $24 \mathrm{~h}$.

Bioassay - Each root extract (medulla and bark) were homogeneized using $100 \mu \mathrm{l}$ of distilled water in microcentrifuge tubes, then diluting in water to the appropriate concentration $(13,25,50,100,150,200,250 \mu \mathrm{g} /$ $\mathrm{ml}$ ). Thirty larvae were then pipetted into each $20 \mathrm{ml}$ volume and observed for a maximum of $24 \mathrm{~h}$, when mortality was recorded. Larvae were considered dead or moribund if they stopped moving for a prolonged period even after gentle probing with a small spatula, as described in the World Health Organization's technical report series. Larvae maintained in distilled water were used as a control. All experiments were run in triplicate. $\mathrm{LC}_{50}$ and $\mathrm{LC}_{90}$ were calculated using probit analysis (Armitage \& Berry 1987); $\mathrm{LT}_{50}$ was calculated using GraphPad Prism computer program (GraphPad Software Incorporated 1995).

Light microscopy and transmission electron microscopy - Histopatological effects of ingestion of D. игиси root bark $(150 \mu \mathrm{g} / \mathrm{ml}$ in water suspension) were studied on midguts of Ae. aegypti larvae. After $4 \mathrm{~h}$ of treatment, the midguts were fixed in $2.5 \%$ glutaraldehyde, $0.1 \mathrm{M}$ sodium cacodylate, $\mathrm{pH} 7.2$ for $12 \mathrm{~h}$ at room temperature. After several washes with the corresponding buffer, they were post-fixed in $1 \%$ osmium tetroxide plus $0.8 \%$ potassium ferrocyanide (1:1) for $1 \mathrm{~h}$ at room temperature. Tissue samples were then dehydrated in a graded series of acetone. Epon resin was used for embedding, and thick sections of $0.6 \mu \mathrm{m}$ were cut using a diamond knife. The sections were stained with $0.1 \%$ toluidine blue and examined using a conventional light microscope. Also, thin sections of $70 \mathrm{\eta m}$ were cut with diamond knife using an Ultracut S (Reichert) ultramicrotome, stained with uranyl acetate for $40 \mathrm{~min}$, lead citrate for $3 \mathrm{~min}$, and photographed using a Zeiss 900 transmission electron microscope at 80 $\mathrm{kV}$ electron acceleration. Larvae maintained in $1 \%$ latex beads were used as a control.

Sequential extraction of PM proteins - Fourth instar Ae. aegypti larvae were maintained in $D$. urucu root bark aqueous suspension $(150 \mu \mathrm{g} / \mathrm{ml})$ for $2 \mathrm{~h}$ (passage time of food bolus throughout the gut). Larvae fed with $1 \%$ latex suspension were used as a control. One hundred and fifty PMs from each treatment were homogenized and sequentially centrifuged $\left(22000 \mathrm{x} \mathrm{g}, 5 \mathrm{~min}, 4^{\circ} \mathrm{C}\right)$ using buffer A: $100 \mathrm{mM}$ Tris- $\mathrm{HCl}, \mathrm{pH} 7.5 / \mathrm{NaCl} 150 \mathrm{mM} / 5 \mathrm{mM}$ ethylenediaminetetraacetic acid (EDTA)/0.1 mM phenylmethylsulfonylffluoride (PMSF), and buffer B: 100 $\mathrm{mM}$ Tris-HCl, $\mathrm{pH}$ 7.5/4\% Sodium docecyl sulfate (SDS)/ $0.1 \mathrm{mM}$ (PMSF). Following the extractions, the supernatants containing the released proteins were Trichloroacetic acid (TCA) precipitated and analyzed by silver stained Tricine-SDS-PAGE (Schägger \& von Jagow 1987).

\section{RESULTS AND DISCUSSION}

The mosquito larvae secrete a layer of non-cellular material which separates the food from the epithelial cells of the gut. This layer is called peritrophic matrix PM. The PM acts as a protective barrier against various chemical, physical and microbial food components (Peters 1992). In this study, larval mortality caused by methanol extract of D. игиси appears to be related to disruption of PM structure and rupture of midgut cells.

Aqueous suspensions of different concentrations of D. urucu bark and medulla root extract were tested against fourth instar larvae. Dose-response curves obtained after $24 \mathrm{~h}$ of treatment were exponential (Fig. 1A), showing that both extracts were very effective against Ae. Aegypti larvae. Root bark extract was more active than root medulla extract presenting $\mathrm{LD}_{50}$ and $\mathrm{LD}_{90}$ values of $17.6 \mu \mathrm{g} / \mathrm{ml}$; $55.4 \mu \mathrm{g} / \mathrm{ml}$ and $33.32 \mu \mathrm{g} / \mathrm{ml} ; 83.69 \mu \mathrm{g} / \mathrm{ml}$, respectively. Mortality among controls was zero for more than $95 \%$ of the assays, and in no instance did it exceed $10 \%$. Time-response curves, obtained for $250 \mu \mathrm{g} / \mathrm{ml}(100 \%$ of mortality for both extracts), were also exponential (Fig. 1B). LT 50 for $D$. urucu root bark and medulla were approximately $6 \mathrm{~h}$ and $7 \mathrm{~h}$, respectively.
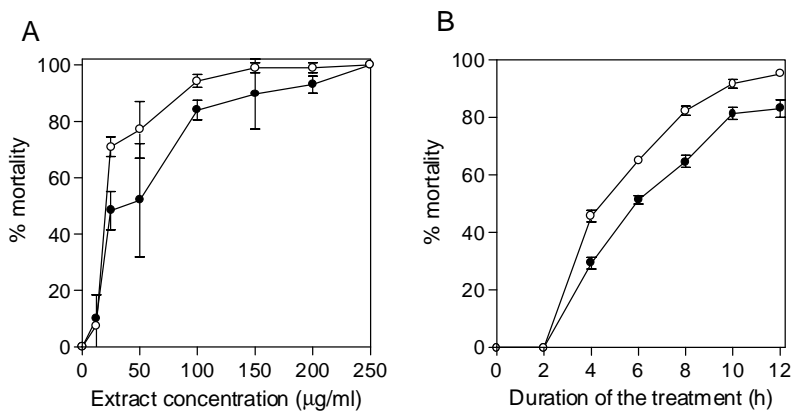

Fig. 1: effect of Derris urucu aqueous suspension on Aedes aegypti larval mortality. A: effect of different concentrations of $D$. urucu root bark (open circle) and medulla (closed circle) aqueous suspension after $24 \mathrm{~h}$ of treatment; B: time course of larvae mortality using $250 \mu \mathrm{g} / \mathrm{ml}$ of $D$. urucu root bark (open circle) and medulla (closed circle) aqueous suspension. 
In mosquito larvae, excreted food residues are enveloped by PM. Fecal pellets of mosquito larvae are rod-like shape when they are fed inert particles (Fig. 2A). Larvae fed with extracts of $D$. игиси excreted a large amount of amorphous feces (Fig. 2B). Control larvae, maintained in distilled water did not produce feces. Modified fecal pellets started to appear $1 \mathrm{~h}$ after the beginning of the experiments. In Schistocerca gregaria, more than $30 \%$ of the potentially toxic dietary tannins are associated with the PM and discharged with the fecal pellets (Bernays \& Chamberlain 1980). It has been reported that Ae. aegypti larvae of DDT resistant strain produce nine times more PM than the susceptible strain (Abedi \& Brown 1961). Peters (1992) suggests that this enhanced synthesis of PM, induced by the uptake of DDT, is a unusual insect mechanism of resistance. Therefore, the elimination of toxic chemicals enveloped by PM appears to a defensive physiological response of the insect larvae.

Light microscopy resolution was not enough to detect any effect on the PM structure from $D$. urucu-treated larvae (Fig. 3A,B). Its appearance was similar to the control PM (Fig. 3B). Plant extract particles were entirely contained by the thin PM. However, during dissections, the PM of treated-larvae was consistently fragile and difficult to pull out from the midgut.

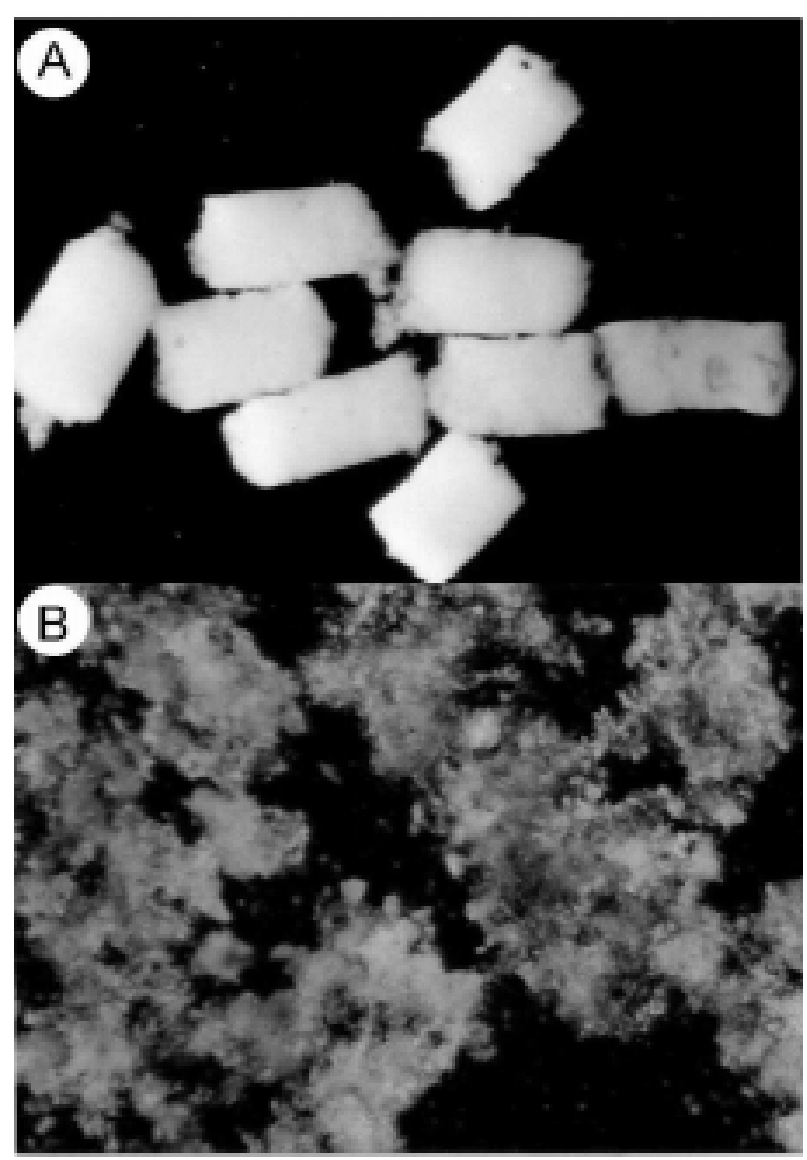

Fig. 2: light micrograph of Aedes aegypti larvae feces. A: fecal pellets with intact peritrophic matrix, obtained after $4 \mathrm{~h}$ feeding with $1 \%$ latex (x 60); B: fecal pellets after $4 \mathrm{~h}$ of treatment with Derris игиси aqueous suspension (x 60).
Electron microscopy of the Ae. aegypti control PM reveals a regular pattern of 5 electron-translucent and 6 electron-dense layers. These are progressively thicker through the epithelium side (Fig. 4A, Peters 1992). The PM from root bark fed mosquitoes is greatly modified (Fig. 4B), probably due to alteration of the chitin meshwork containing pores. The enlarged PM pores allow the passage of ingested food material to midgut epithelium (Harper et al. 1998, Wang \& Granados 2000).
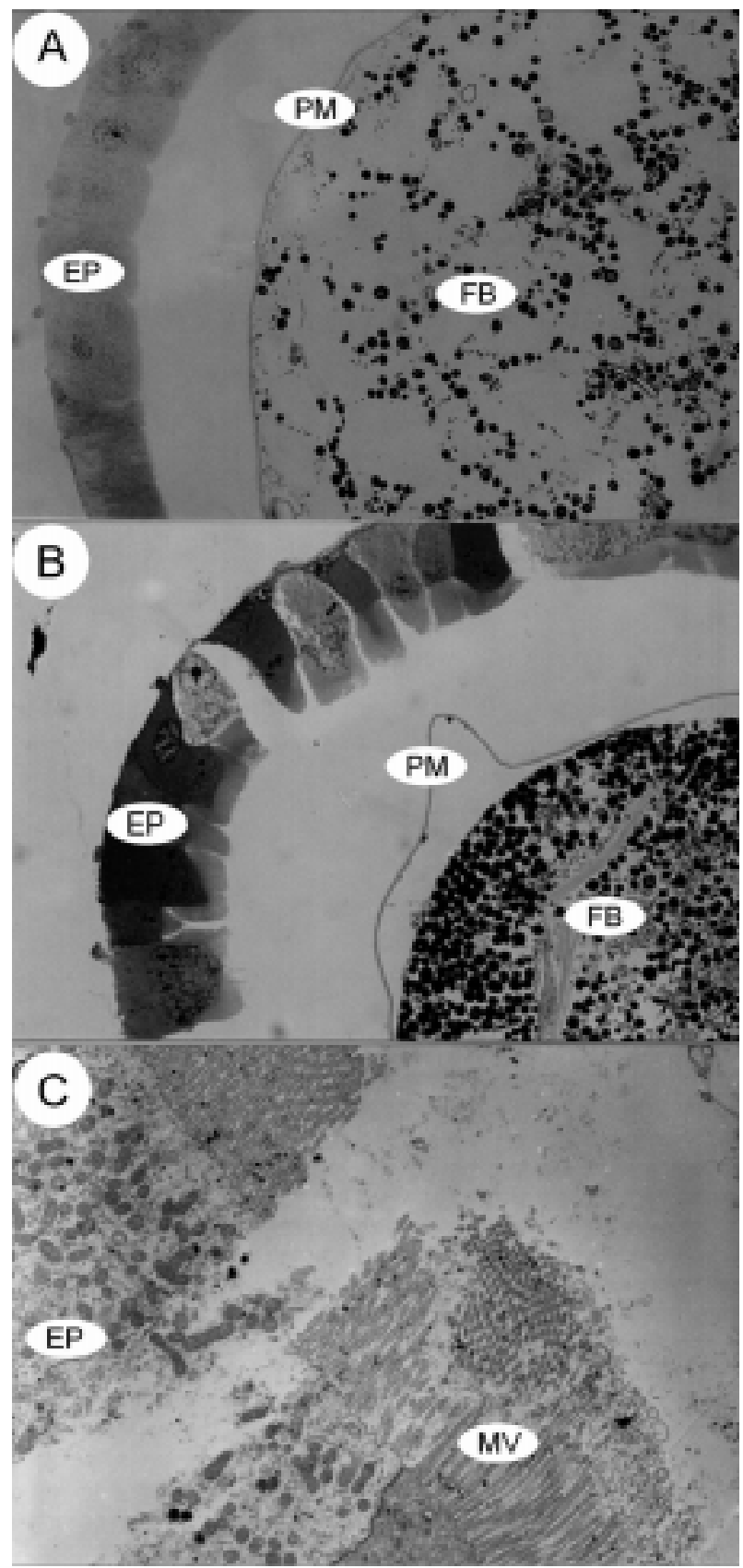

Fig. 3: transversal sections of Aedes aegypti larval midgut. A: light micrograph of larva fed during $4 \mathrm{~h}$ on $1 \%$ latex beads (control; $\mathrm{x}$ 630), and B: larva fed during $4 \mathrm{~h}$ on Derris urucu extract (x 630). The semi-thin sections were stained with toluidine blue; $\mathrm{C}$ : electon micrograph of larva fed as in B (x 12,000) stained with uranyl acetate/lead citrate. EP: epithelium; FB: food bolus; MV: microvilli; PM: peritrophic matrix. 
Light microscopy revealed histological alterations in the midgut epithelium of treated larvae. Fig. 3B shows less stained cells detached from neighbor cells or from the basal lamina. The midgut of untreated larvae is exclusively composed of regular stained columnar cells (Fig. $3 \mathrm{~A})$. Cell damage was most apparent using electron microscopy. Some midgut columnar cells extruded their cytoplasmic contents into the midgut lumen as shown in Fig. 3C. In crickets, rotenone feeding leads to rupture of gastric caecae and Malpighian tubules cells (Greenhalgh

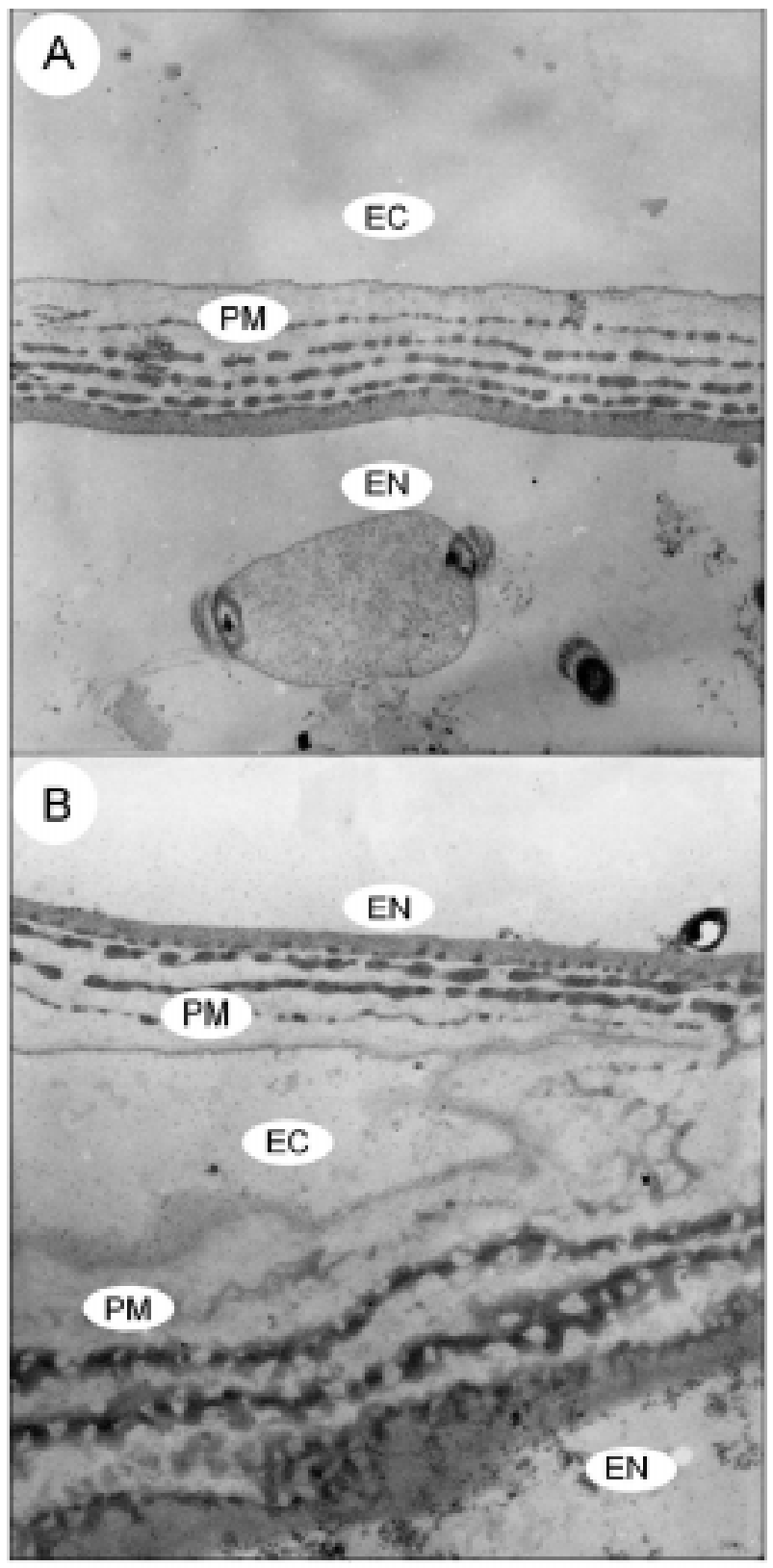

Fig. 4: transversal sections of Aedes aegypti peritrophic matrix. A: transmission electron microscopy of larva fed during $4 \mathrm{~h}$ on $1 \%$ latex beads (control; x 12,000), and B: larva fed during $4 \mathrm{~h}$ on Derris urucu extract (x 12,000) stained with uranyl acetate/lead citrate. EC: ectoperitrophic space (epithelium side); EN: endoperitrophic space (food bolus side); PM: peritrophic matrix
1986). Rotenone action in the fish has been attributed to the epithelium lysis and blockage of circulation of the gills. Rotenone also causes decrease in oxygen consumption in mouse liver (Lindahl \& Öberg 1961).

In order to verify whether the D. urucu root bark extract treatment could also interfere in the interaction of PM and its associated proteins, two buffers were sequentially employed to extract PM proteins according to Elvin et al. (1996). Ae. aegypti proteins are strongly bound to the PM. Few proteins were extractable either by buffer A, or buffer B from control PMs (Fig. 5, lanes 2 and 4). Strongly bound PM proteins were also observed in Trichoplusia ni (Lepidoptera) larvae (Wang \& Granados 2000) and Lucilia cuprina (Diptera) larvae (Elvin et al. 1996). The majority of the total PM proteins from L. cuprina are not solubilized by strong denaturants such as SDS used in our experiments (Tellam et al. 1999). However, in vitro extractions using the same buffers stated above released a significant amount of proteins from PM of $D$. urucu-treated larvae (Fig. 5, lanes 3 and 5). These results suggest that PM disruption by $D$. игиси extract weakened the interaction among PM proteins and other PM constituents, chitin and/or proteoglycans.

The extract of $D$. urucu has already been the subject of phytochemical studies and has been shown to contain insecticidal isoflavonoid-type compounds known as rotenoids (Davidson 1930). In addition to these studies, a bioassay-guided chemical fractionation protocol will be conducted in order to identify further larvicidal components in this extract, mainly those responsible for PM disruption. These metabolites could be used as part of a novel strategy for insect control. Disruption of PM structure could facilitate the transport and enhance the insecticidal activity of different agents such as virus, bacteria, protozoans, toxic proteins and plant secondary metabolites.

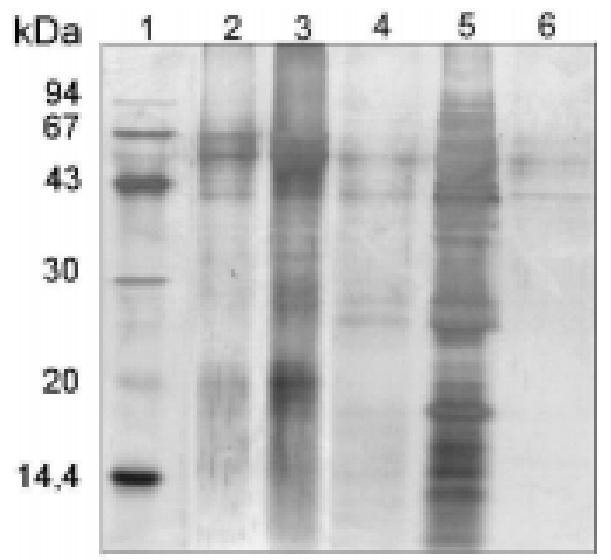

Fig. 5: SDS-PAGE analysis of proteins extracted from Aedes aegypti peritrophic matrix (PM). Molecular mass standard (lane 1); proteins extracted from control PMs (lane 2) and Derris urucu fed larvae PMs (lane 3) with $100 \mathrm{mM}$ Tris- $\mathrm{HCl}, \mathrm{pH} 7.5 / 150 \mathrm{mM} \mathrm{NaCl} /$ $5 \mathrm{mM}$ EDTA/0.1 mM PMSF; proteins extracted from control PMs (lane 4) and D. игиси fed larvae PMs (lane 5) with $100 \mathrm{mM}$ Tris$\mathrm{HCl}, \mathrm{pH} 7.5 / 4 \%$ SDS/0.1 mM PMSF; lane 6: $2 \mathrm{mg}$ of D. игисu root bark extract. Proteins from 150 fifty PMs were loaded on lanes 25. 


\section{ACKNOWLEDGEMENTS}

To Noil Gomes de Freitas for assistance in obtaining the micrographs, Juremito Carvalho de Araújo for mosquito colony maintenance and Dr Richard Ian Samuels for helpful suggestions.

\section{REFERENCES}

Abedi ZH, Brown AWA 1961. Peritrophic membrane as vehicle for DTT and DDE excretion in Aedes aegypti larvae. Ann Entomol Soc Am 54: 539-542.

Armitage P, Berry G 1987. Statistical Methods in Medical Research, 2nd ed., Blackwell Scientific Publications, Oxford, $559 \mathrm{pp}$.

Balandrin MF 1985. Natural plant chemicals: sources of industrial and medicinal materials. Science 228: 1154-1160.

Barbehenn RV, Martin MM 1997. Permeability of the peritrophic envelopes of herbivorous insects to dextran sulfate: a test of the polyanion exclusion hypothesis. $J$ Insect Physiol 43: 243-249.

Beattie DS, Obungu VH, Kiaira JK 1994. Oxidation of NADH by a rotenone and antimycin-sensitive pathway in the mitochondrion of procyclic Trypanosoma brucei brucei. Mol Biochem Parasitol 64: 87-94.

Beier JC 1998. Malaria parasite development in mosquitoes. Annu Rev Entomol 43: 519-543.

Bernays EA, Chamberlain DJ 1980. A study of tolerance of ingested tannin in Schistocerca gregaria. J Insect Physiol 26: 415-420.

Davidson WM 1930. Rotenone as a contact inseticide. J Econ Entomol 23: 868-874.

Derksen ACG, Granados RR 1988. Alteration of a lepidopteran peritrophic membrane by baculoviruses and enhancement of viral infectivity. Virology 167: 242-250.

Elvin CM, Vuocolo T, Pearson RD, East IJ, Riding GA, Eisemann CH, Tellam RL 1996. Characterization of a major peritrophic membrane protein, peritrophin-44, from the larvae of Lucilia cuprina. J Biol Chem 271: 8925-8935.

Greenhalgh EA 1986. The effects of chlordane and rotenone on the alimentary tract of the field cricket. Toxicology 42: 317330.

Harper MS, Hopkins TL, Czapla TH 1998. Effect of wheat germ agglutinin on formation and structure of the peritrophic membrane in european corn borer (Ostrinia nubilalis) larvae. Tissue \& Cell 30: 166-177.
Lehane MJ 1997. Peritrophic matrix structure and function. Annu Rev Entomol 42: 525-550.

Lindahl PE, Öberg KE 1961. Effect of rotenone on respiration and its point of attack. Exp Cell Res 23: 228-237.

Palchick S 1996. Chemical control of vectors. In JB Beaty, WC Marquardt (eds), The Biology of the Disease Vectors, University Press of Colorado, Colorado, p. 502-511.

Peters W 1992. Peritrophic membranes. In SD Bradshaw, W Burggren, HC Heller, S Ishii, H Langer, G Neuweiler, DJ Randall (eds), Zoophysiology, vol. 30, Springer-Verlag, Berlin, $238 \mathrm{pp}$.

Pimenta PFP, Modi GB, Pereira ST, Shahabuddin M, Sacks DJ 1997. A novel role for the peritrophic matrix in protecting Leishmania from the hydrolytic activities of the sand fly midgut. Parasitology 115: 359-369.

Regev A, Keller M, Strizhov N, Sneh B, Prudovsky E, Chet I, Ginzberg I, Koncz-Kalman Z, Koncz C, Schell J, Zilberstein A 1996. Synergistic activity of a Bacillus thuringiensis deltaendotoxin and a bacterial endochitinase against Spodoptera littoralis larvae. Appl Environ Microbiol 62: 3581-3586.

Richards AG, Richards PA 1977. The peritrophic membranes of insects. Ann Rev Entomol 22: 219-240.

Schägger H, von Jagow G 1987. Tricine-sodium dodecyl sulfate-polyacrylamide gel electrophoresis for the separation of proteins in the range from 1 to $100 \mathrm{kDa}$. Anal Biochem 166: 368-379.

Shahabuddin M, Lemos FJA, Kaslow DC, Jacobs-Lorena M 1996. Antibody-mediated inhibition of Aedes aegypti midgut trypsins blocks sporogonic development of Plasmodium gallinaceum. Infection and Immunity 64: 739-743.

Sukamar K, Perich MJ, Boobar LR 1991. Botanical derivatives in mosquito control: a review. J Amer Mosq Control Ass 7: 210-237.

Tellam RL 1996. The peritrophic matrix. In MJ Lehane, PF Billingsley (eds), Biology of the Insect Midgut, Chapman \& Hall, London, p. 86-114.

Tellam RL, Wijffels G, Willadsen P 1999. Peritrophic matrix proteins. Insect Biochem Mol Biol 29: 87-101.

Terra WR 1996. Evolution and function of insect peritrophic membrane. Ci Cult 48: 317-324.

Terra WR 2001. The origin and functions of the insect peritrophic membrane and peritrophic gel. Arch Insect Biochem Physiol 47: 47-61.

Wang P, Granados RR 2000. Calcofluor disrupts the midgut defense system in insects. Insect Biochem Mol Biol 30: 135143 . 